\title{
Influence of Material Composition on Flame Spread Behavior over Combustible Solid of Paper/Bagasse
}

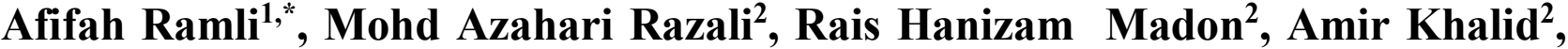 \\ Md Norrizam Mohmad Ja'at ${ }^{2}$, Bukhari Manshoor ${ }^{2}$
}

\author{
${ }^{1}$ Faculty of Mechanical \& Manufacturing Engineering, Universiti Tun Hussein Onn Malaysia, Parit Raja, Batu Pahat, \\ Johor, 86400, MALAYSIA. \\ ${ }^{2}$ Centre for Energy and Industrial Environment Studies (CEIES), Faculty of Mechanical \& Manufacturing Engineering \\ Universiti Tun Hussein Onn Malaysia, Parit Raja, Batu Pahat, Johor, 86400, MALAYSIA.
}

Received 21 December 2017; accepted 23 July 2018, available online 30 December 2018

\begin{abstract}
Fire Safety Engineering is an application of science to improve the safety from the destructive effect of the fire. Paper is one of sources that easily catch fire, however, research on flame spread towards paper is still not enough to describe about the phenomenon. Inspiration from this, the behavior of downward flame spread over paper/bagasse is experimentally investigated. Composition of $0 \%, 30 \%, 50 \%, 70 \%$ and $100 \%$ bagasse is chosen for this research. Flame spread behavior for each composition is analyzed from the observation. Results show for each composition, the flame spreads with "U" shape at the beginning of combustion until the whole specimen. The result shows that the flame spread rate decreases as bagasse composition increases. The highest flame spread is $0.813 \mathrm{~mm} / \mathrm{s}$ for pure paper and the lowest one is $0.481 \mathrm{~mm} / \mathrm{s}$ for pure bagasse. Not only that, it also shows the flame spread rate decreases as the density increases. It is clarified that density for bagasse is higher than paper. Result infers that the flame spread shape and rate are not only influenced by the bagasse composition but also by the density.
\end{abstract}

Keywords: Flame spread behavior, flame spread rate, combined fiber

\section{Introduction}

Flame spread behavior over combustible solid is one of important factor in fire that related to Fire Safety Engineering [1-2]. About 5817 cases that involved in a building fire have been recorded by Malaysian Fire and Rescue Department. One of the factors that contributed to this fire happen is paper [3]. According to this, it is necessary to understand the flame spread behavior over this material in order to improve the technical capability for fire preventions. At this stage, the fundamental approach is required which can be applied at the design stage [4]. The better understanding of the flame spread structure is required in order to provide useful information towards combustion process from an engineering standpoint [5-14]

There are several studies have been conducted on flame spread over combustible solid and the phenomenon have been may be classified in several ways, such as physically, chemically, geometrically, and dynamically [15-19]. Previously, the effect of thickness on downward flame spread towards paper has been conducted based on

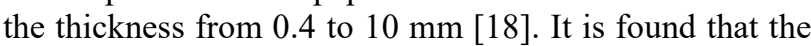
flame spread is initiated to transpire for specimen thickness below $8.4 \mathrm{~mm}$ under the state of natural convection and the flame spread is turned out to be unsteady when the thickness is over $8.4 \mathrm{~mm}$. Takahashi et al. Examined the flame spread behavior headed for thin paper disk in the narrow space for both upwards and downward flame spread [16]. When the leading edge comes 15-20 mm from the center of paper disk, the flame spread decreases. Gollner et al. made experiment to examine the upward flame spread over corrugated cardboard [20]. The result proves that the nonhomogeneity of the cardboard is assisted to diminish the acceleration of the upward spread rates by physically disorganized stream in the boundary layer close by to the vertical surface and thereby modifying heating rates of the solid fuel above the pyrolysis region. Thus, there are researches that have been investigated the flame spread over fabric. The studies infer the thread angle dependency towards the fabric $[4,21,22]$. It is obtained that material and thread angle have some influence on the flame spread behavior over fabric.

Currently, paper has been produced by using other natural fiber in order to save the earth and to control the ecosystem of the world [23]. Several researches have been conducted by using banana leaves [24], palm fiber [25], and elephant's skin as an alternative to produce paper. However, all these studies are focused only on the mechanical properties of the paper. Instead of the mechanical properties, the study about the behavior of flame spread is also essential for fire safety engineering; which is still lack of attention to be carried out. 
Thus, in this experiment, flame spread behavior over paper/bagasse composite has been scrutinized. The bagasse is chosen in the research according to the number of cellulose, hemicellulose, lignin and small amount of extracts and mineral salts that constitute from the bagasse [26]. The objective of this experiment is to examine the effect of the composition of bagasse on the flame spread shape and flame spread rate. As conclusion, reasons influence the behavior of flame spread on this composite sample have been discussed.

\section{Experimental Setup}

This investigation has been conducted to explore the flame spread behaviour towards composite solid of paper/bagasse. Specimens have been made with $0 \%$, $30 \%, 50 \%, 70 \%$, and $100 \%$ of bagasse composition. The size of the specimen used in this experiment is $10 \mathrm{~cm} \times 10$ $\mathrm{cm}$ and the thickness is determined about $0.07 \mathrm{~cm}$.

Both bagasse and paper have been cleaned first in order to get rid of any dirt and soaked in Sodium Hydroxide $(\mathrm{NaOH})$ that has been diluted in hot water for 24 hours (one day). Next, the mixture is blended about 20 minutes. The sample then is placed on the net, which prepared by the wooden frame. It is purposely done to get rid of the liquid contained in the specimen to speed up the drying process. Then, the specimen sheet has been dried at room temperature.

Each specimen is examined by using the Scanning Electron Microscope JEOL (SEM) to analyze each of the specimen sheet structures. Specimen sheet has been tested by using Vertical Flame Chamber as shown in the schematics in Fig. 1. The camera is used to record the vertical downward flame spread in the period of the experiment of each specimen's sheet until the completion of combustion and it is recorded from the front view. The flame spread is analyzed based on the recorded video.

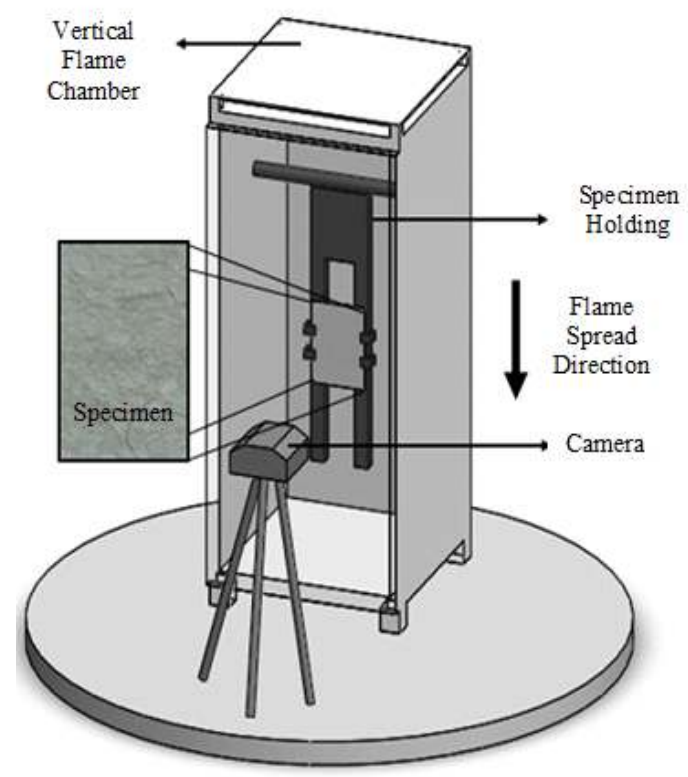

Fig 1 Schematics of experimental setup.

\section{Results and Discussion}

\subsection{Flame Spread Behavior}

The sample is ignited at a point on its top edge as the flame spreads in the downward direction. Figure 2 shows the pattern of flame spread for different composition of bagasse. It is seen each composition has different shape of flame spread [2]. The shape of flame spread may be affected by the phenomenon during the combustion process.

Figure 3 shows the detailed observation of flame shape for every $15 \mathrm{~s}$. The shape is determined based on the leading edge of flame spread. The solid and the dash lines represent the flame shape during combustion and when the flame extinguishes, respectively. Figure 3(a) shows flame spreads for pure paper. It is seen that the flame spreads continuously through the whole combustion process. Starting of the combustion, the flame spreads in "U" shape and turns to flat shape after the flame spreads to whole specimen. The flame spread remains until the end of the specimen. For other composition of bagasse, as seen in Fig. 3 (b) to (e), the flame also starts with " $U$ " shape at the beginning of the experiment. However, the flame extinguishes during the combustion process. During the experiment, the flame needs to be ignited several times due to this phenomenon.

The result infers that the flame spread phenomenon is influenced by bagasse composition. In order to examine this effect, each specimen is analyzed by SEM before the combustion testing. Figure 4 shows microstructure image for different bagasse compositions. SEM is used in this experiment in order to verify the size of the paper fibre and bagasse fiber since the size of the fiber has strongly influenced in the flame retardant [27]. It is seen in Figs. 4 (a) and (c) that the pure paper has smaller size of fiber than the one of pure bagasse. This difference in size is supposed to be significant factor influences on the flame spread phenomenon between the pure paper and pure bagasse. A similar effect is seen also for mixture composition. Both of the fibers are mixed in the sample as shown in Fig. 4 (b), where the yellow circle is the example of bagasse fiber. It is seen that flammability of the composition is related to the big size of bagasse fiber.

\subsection{Flame Spread Rate}

Figure 5 shows the relationship between flame spread rate and bagasse composition. Flame spread rates are determined by measuring the location of the supreme preceding point of the burning front at each time. The result shows that the flame spread rate decreases as the composition increases. The higher flame spread rate is pure paper, follows with $30 \%, 50 \%, 70 \%$ and pure bagasse; the flame spread rate is $0.813 \mathrm{~mm} / \mathrm{s}, 0.703$ $\mathrm{mm} / \mathrm{s}, \quad 0.551 \mathrm{~mm} / \mathrm{s}, \quad 0.505 \mathrm{~mm} / \mathrm{s}$ and $0.481 \mathrm{~mm} / \mathrm{s}$, respectively. Result infers that the flame spread pattern and the flame spread rate have been strongly influenced by bagasse. 
Based on the previous study, the flame spread rate is believed to be related with density of the sample. According to Daniel Gross, the flame spread rate decreases as the density increases [28]. Figure 6 shows the connection concerning the flame spread rate and the density. It is seen that the result of this experiment seems to have the similar dependency as the previous research. Bagasse fibre has high density compared to paper fibre; which reduces the flame spread rate.

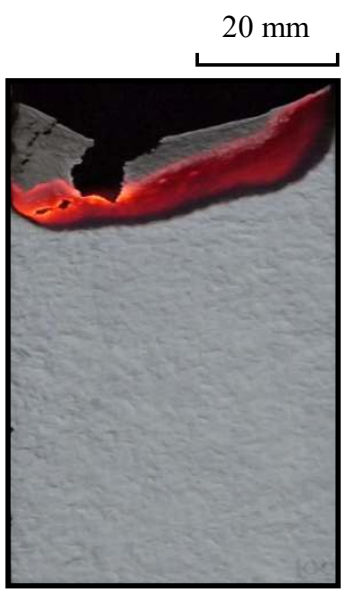

(a) $0 \%$ of Bagasse

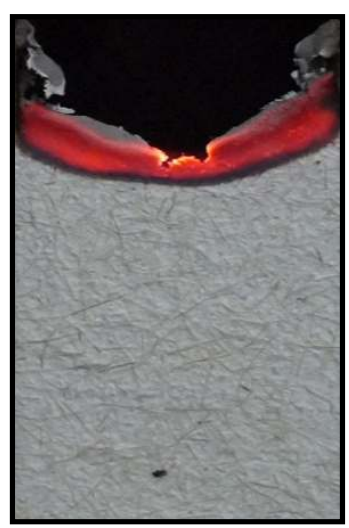

(c) $50 \%$ of Bagasse

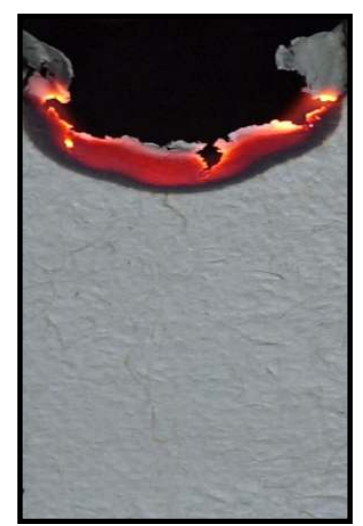

(b) $30 \%$ of Bagasse

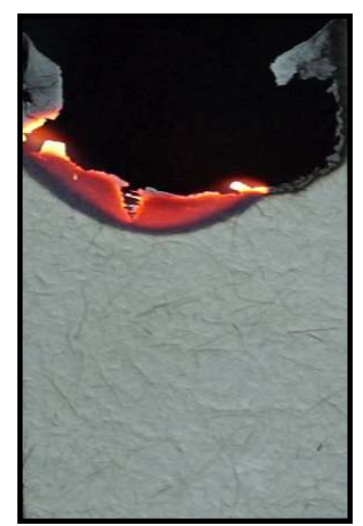

(d) $70 \%$ of Bagasse

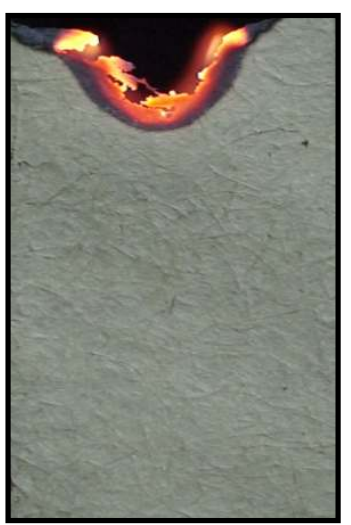

(e) $100 \%$ of Bagasse

Fig. 2 Flame spread shape for different bagasse compositions.

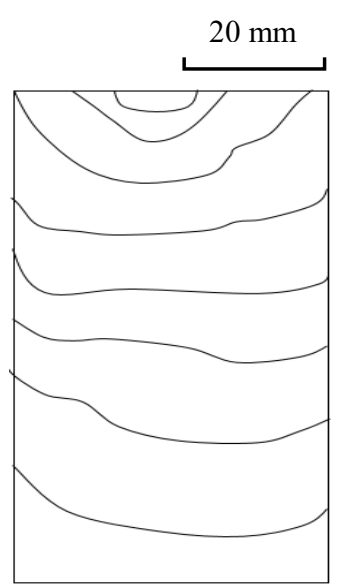

(a) $0 \%$ of Bagasse

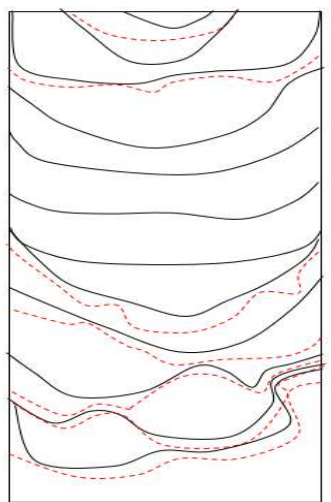

(c) $50 \%$ of Bagasse

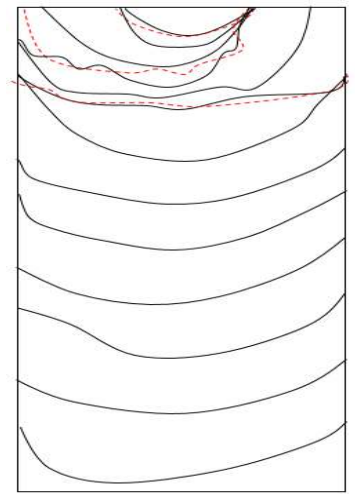

(b) $30 \%$ of Bagasse

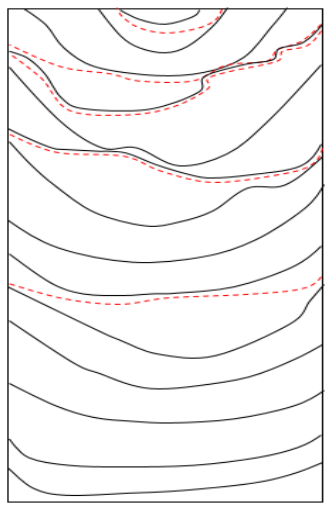

(d) $70 \%$ of Bagasse

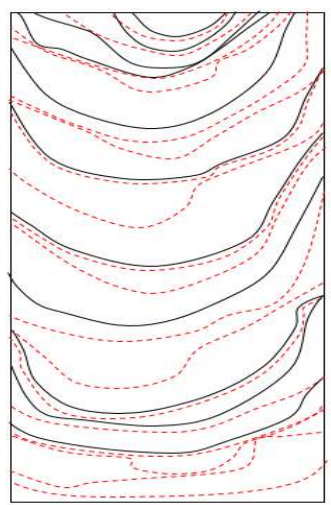

(e) $100 \%$ of Bagasse

Flame

- - - Extinguished flame

Fig. 3 Flame spread for every $15 \mathrm{~s}$ between different bagasse compositions. 


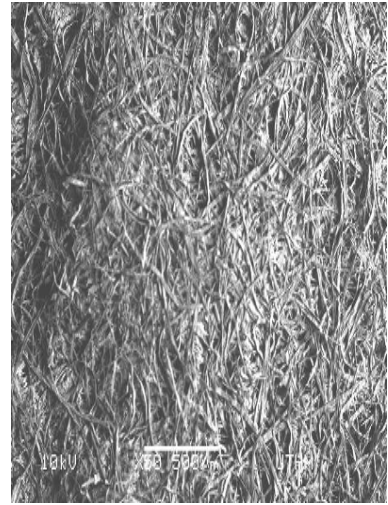

(a) $0 \%$ of Bagasse

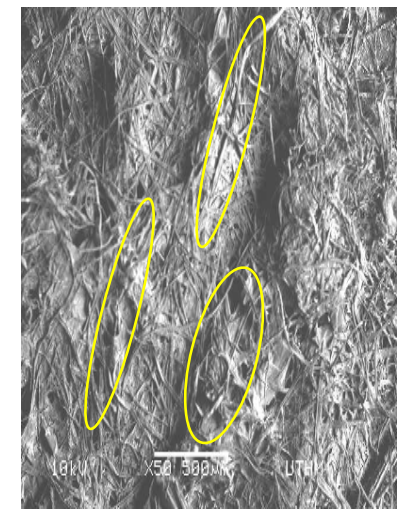

(b) $50 \%$ of Bagasse

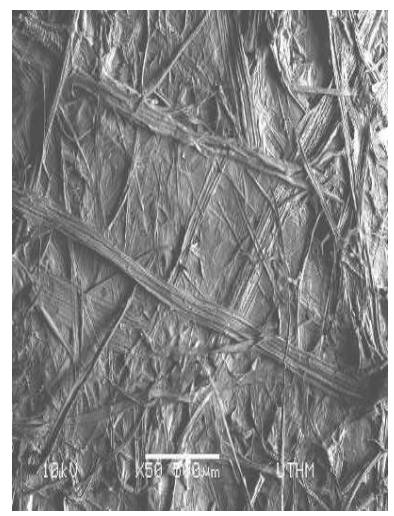

(c) $100 \%$ of Bagasse

Fig. 4 Microstructure image for different bagasse composition.

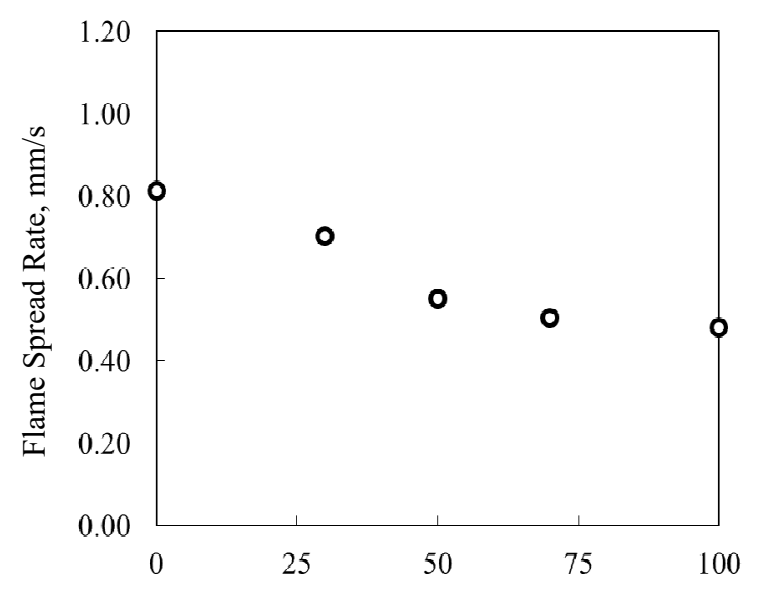

Composition of Bagasse (\%)

Fig 5 Relationship between flame spread rate and composition of bagasse.

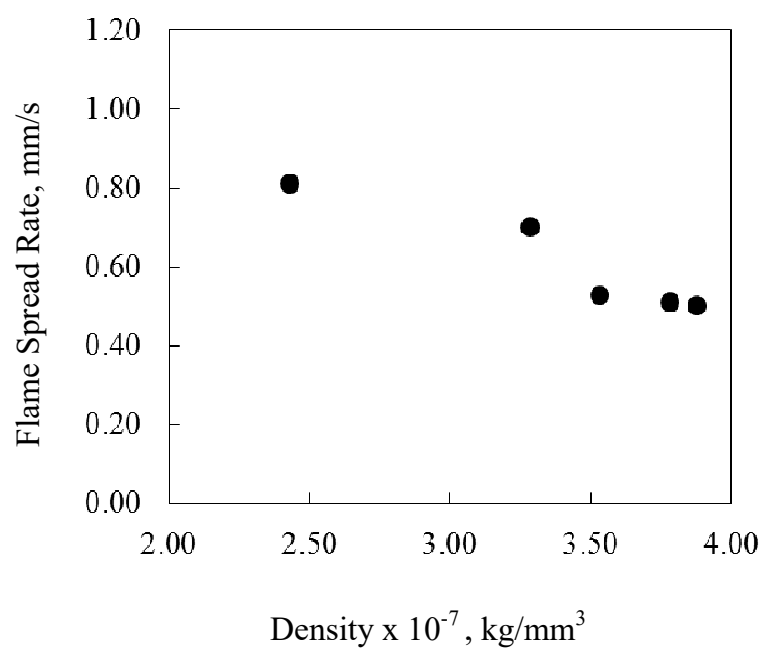

Fig 6 Relationship between flame spread rate and density.

\section{Conclusion}

In this study, flame spread over paper/bagasse is examined and following results are obtained:

i. Shapes of flame front differ between samples. Pure paper burns and flame spreads in ' $U$ ' shape. However, flame is distinguished for $30 \%, 50 \%$, $70 \%$ and $100 \%$ bagasse composition.

ii. Flame spread rate decreases as bagasse composition increases. Results infer the bagasse has significant influences on not only the flame spread shape, but also on the flame spread rate.

\section{Acknowledgment}

The authors would like to thank Universiti Tun Hussein Onn Malaysia (UTHM) and Ministry of Higher Education Malaysia (MOHE) for their financial support of the present work through Fundamental Research Grant Scheme (FRGS-1465).

\section{References}

[1] Charuchinda, S., Suzuki, M. \& Dobashi, R. (2001). Behavior of flames spreading downward over napped fabrics. Fire Safety Journal, 36, 313-325.

[2] JBPM Website Malaysia. JBPM Website Search. http://www.bomba.gov.my (accessed 13 Disember 2013)

[3] Mohd Azahari, R., Sofian, M., Azwan, S., Akmal Nizam, M., Ahmad Husaini, A., Mohd Faisal, H., Norrizam, J. \& Amir, K. (2017). Flame spread behavior over combustible thick solid of paper, bagasse and mixed paper / bagasse. IOP Conference Series: Materials Science and Engineering, 243 (1), 012026.

[4] Mohd Azahari, R., Azwan, S., Akmal Nizam, M., Mohd Faisal, H., Hamidon, S. \& Hazahir, P. (2017). Effect of Thread Angle on Flame Spread Behavior over Combined Fabric of Kenaf/Polyester. AIP Conference Proceedings, 1831(1), 020016.

[5] Zhao, X., Liao, Y.T., Johnston, M.C., James, S.T., Ferkul, P. V. \& Olson, S.L. (2017). Concurrent flame 
growth, spread, and quenching over composite fabric samples in low speed purely forced flow in microgravity. Proceedings of the Combustion Institute, 36, 2971-2978.

[6] Avinash, G., Kumar, A. \& Raghavan, V. (2016). Experimental analysis of diffusion flame spread along thin parallel solid fuel surfaces in a natural convective environment. Combustion and Flame, 165, 321-333.

[7] Bhattacharjee, S., Tran, W., Laue, M., Paolini, C. \& Nakamura, Y. (2015). Experimental validation of a correlation capturing the boundary layer effect on spread rate in the kinetic regime of opposed-flow flame spread. Proceedings of the Combustion Institute, 35, 2631-2638.

[8] Comas, B., Carmona, A. \& Pujol, T. (2015). Experimental study of the channel effect on the flame spread over thin solid fuels. Fire Safety Journal, 71, 162-173.

[9] Hou, Y., Cheng, X., Liu, S., Liu, C. \& Zhang, H. (2015). Experimental study on upward flame spread of exterior wall thermal insulation materials. Energy Procedia, 66, 161-164.

[10]Hu, L., Lu, Y., Yoshioka, K., Zhang, Y., Fernandezpello, C., Ho, S. \& Fujita, O. (2017). Limiting oxygen concentration for extinction of upward spreading flames over inclined thin polyethyleneinsulated $\mathrm{NiCr}$ electrical wires with opposed-flow under normal- and micro-gravity. Proceedings of the Combustion Institute, 36, 3045-3053.

[11] Jae, S., Kim, M., Park, J., Fujita, O. \& Chung, S. (2015). Flame spread over electrical wire with AC electric fields: Internal circulation, fuel vapor-jet, spread rate acceleration, and molten insulator dripping. Combustion and Flame, 162, 1167-1175.

[12] Kleinhenz, J., Feier, I.I., Hsu, S., James, S.T., Ferkul, P. V. \& Sacksteder, K.R. (2008). Pressure modeling of upward flame spread and burning rates over solids in partial gravity. Combustion and Flame, 154, 637643.

[13]Kumar, A., Shih, H.Y. \& T'ien, J.S. (2003). A comparison of extinction limits and spreading rates in opposed and concurrent spreading flames over thin solids. Combustion and Flame, 132, 667-677.

[14] Maruyama, Y., Joe, M. \& Yokomori, T. (2013). Experimental investigation of flame spreading over pure methane hydrate in a laminar boundary layer. Proceedings of the Combustion Institute, 34, 21312138.

[15] Ayani, M.B., Esfahani, J.A. \& Mehrabian, R. (2006). Downward flame spread over PMMA sheets in quiescent air: Experimental and theoretical studies. Fire Safety Journal, 41, 164-169.

[16] Takahashi, T., Daitoku, T. \& Tsuruda, T. (2017). Behavior of the flame spread along a thin paper-disk in a narrow space. Proceedings of the Combustion Institute, 36, 3011-3017.

[17] Bhattacharjee, S., Paolini, C., Tran, W., Ray, J. \& Takahashi, S. (2015). Temperature and $\mathrm{CO}_{2}$ fields of a downward spreading flame over thin cellulose : A comparison of experimental and computational results. Proceedings of the Combustion Institute, 35, 2665-2672.

[18] Suzuki, M., Dobashi, R. \& Hirano, T. (1994). Behavior of fires spreading downward over thick paper. Symposium (International) on Combustion, 25 (1), 1439-1446.

[19] Gong, J., Zhou, X., Li, J. \& Yang, L. (2015). Effect of finite dimension on downward flame spread over PMMA slabs: Experimental and theoretical study. International Journal of Heat and Mass Transfer, 91, 225-234.

[20] Gollner, M.J., Williams, F.A. \& Rangwala, A.S. (2011). Upward flame spread over corrugated cardboard. Combustion and Flame, 158, 1404-1412.

[21] Mohd Azahari, B. R., Azwan, B. S., Mohd Faisal, B. H., Amir, B. K., Suzuki, M. \& Masuda, W. (2015). Flame spread behavior over combined fabric of cotton/polyester. International Engineering Research and Innovation Symposium, 1-5.

[22] Mohd Azahari, B.R., Amir, B.K., Suzuki, M., Masud, W., Hamidon, B.S. \& Azwan, B.S. (2017). Effect of Synthetic Material on Angle Dependency of Flame Spread Behavior over Combined Fabric. AIP Conference Proceedings, 1831 (1), 020014.

[23] Wahab, S., Yusuf, Y., Ahmad, R., Mustapa, S. \& Tahar, M.S. (2012). Producing Paper using Pineapple Leaf Fiber. Advanced Materials Research, 390, 3382-3386.

[24] Yosephine, A., Gala, V., Ayucitra, A. \& Retnoningtyas, E.S. (2012). Pemanfaatan ampas tebu dan kulit pisang dalam pembuatan kertas serat campuran. Jurnal Teknik Kimia Indonesia, 11 (2), 94-100.

[25] Syamsu, K., Haditjaroko, L., Pradikta, G.I. \& Roliadi, H. (2014). Campuran pulp tandan kosong kelapa sawit dan selulosa mikrobial nata de cassava dalam pembuatan kertas. Jurnal Ilmu Pertanian. Indonesia, 19, 14-21.

[26] Mandelli, F., Brenelli, L.B., Almeida, R.F., Goldbeck, R., Wolf, L.D., Hoffmam, Z.B., Ruller, R., Rocha, G.J.M., Mercadante, A.Z. \& Squina, F.M. (2014). Simultaneous production of xylo oligo saccharides and antioxidant compounds from sugarcane bagasse via enzymatic hydrolysis. Industrial Crops and Products, 52, 770-775.

[27] Hongdian, L., Lei, S. \& Yuan, H. (2011). A review on flame retardant technology in China. Part II: flame retardant polymeric nanocomposites and coatings. Polymers Advanced Technologies, 22 (4), 379-394.

[28] Quintiere, J., Harkleroad, M. \& Haserni, Y. (1986). Wall flames and implications for upward flame spread. Combustion Science and Technology, 48, 191-222. 